Electronic Supplementary Information (ESI)

\title{
Green Electroluminescence from Charged Phenothiazine Derivative
}

Kanagaraj Shanmugasundaram, ${ }^{\mathrm{a}}$ Madayanad Suresh Subeesh, ${ }^{\mathrm{a}}$ Chozhidakath Damodharan

Sunesh, ${ }^{a}$ Ramesh Kumar Chitumalla, ${ }^{\mathrm{b}}$ Joonkyung Jang, ${ }^{\mathrm{b}}$ Youngson Choe*a

${ }^{a}$ School of Chemical and Biomolecular Engineering, Pusan National University, Busan 609-735, Republic of Korea.

${ }^{b}$ Department of Nanoenergy Engineering, Pusan National University, Busan, 609-735, Republic of Korea.

* Corresponding author: Prof. Youngson Choe

Email: choe@pusan.ac.kr

Tel.: +8251510 2396;

Fax: +8251 5128634 . 


\section{Table of contents}

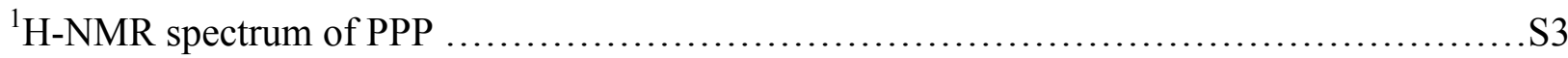

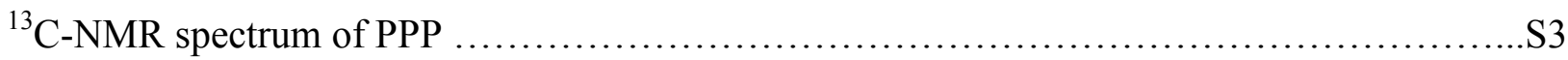

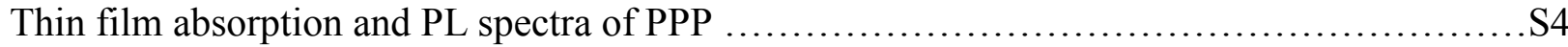

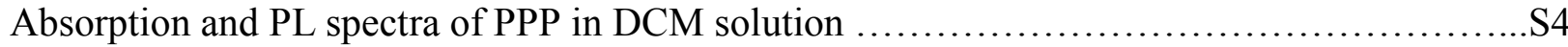

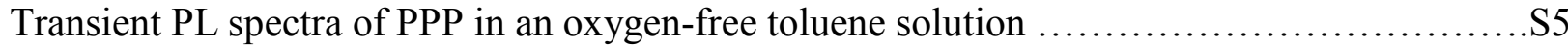

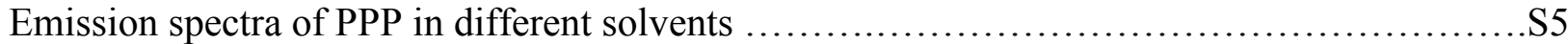

The DFT optimized ground state geometry of the compound PPP .......................... 6

The UV-visible absorption spectrum of PPP simulated in dichloromethane .................S6

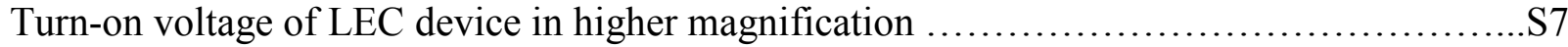

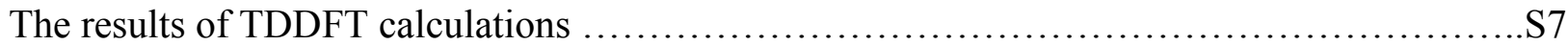




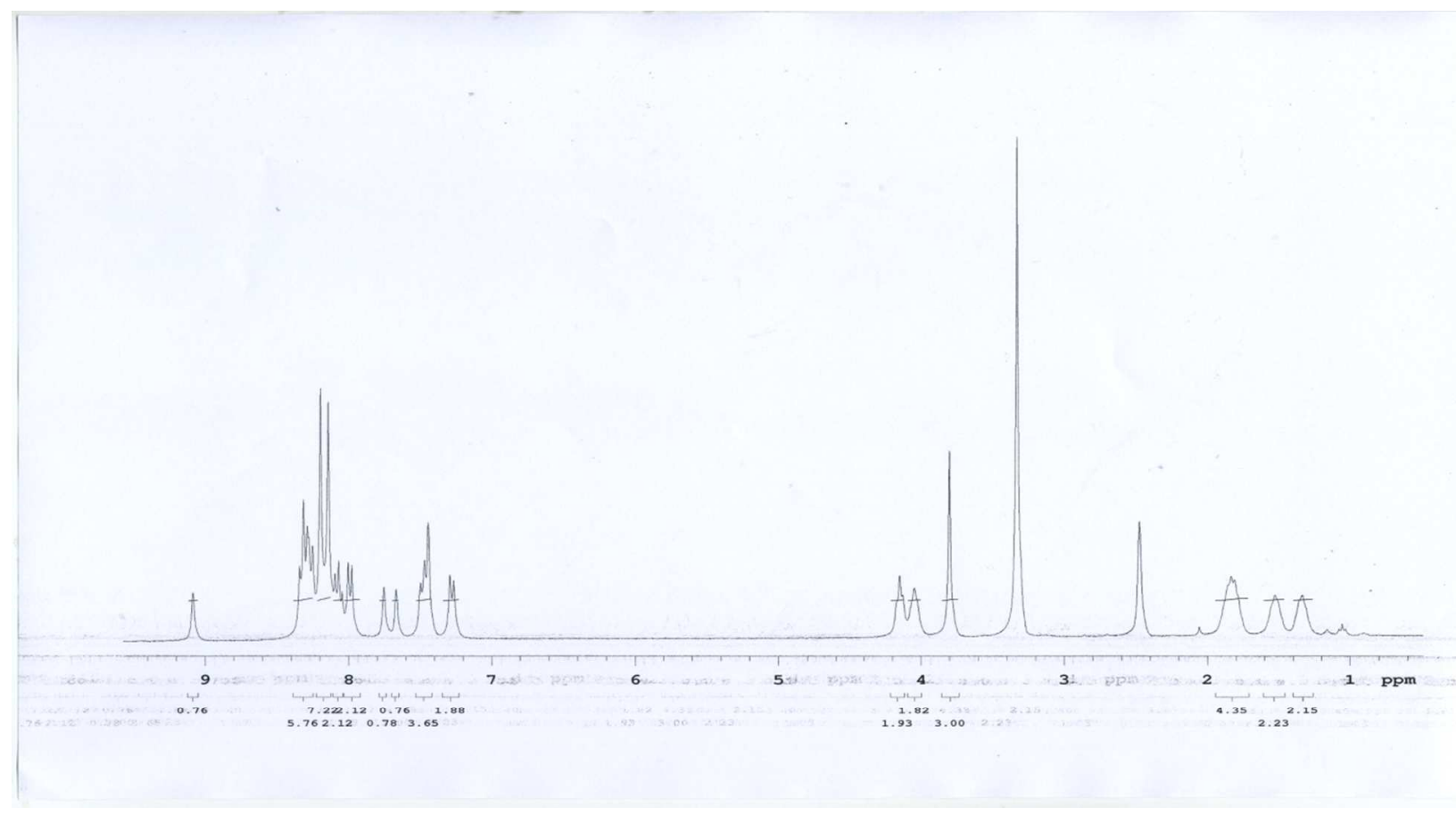

Figure S1. ${ }^{1} \mathrm{H}-\mathrm{NMR}$ spectrum of PPP.

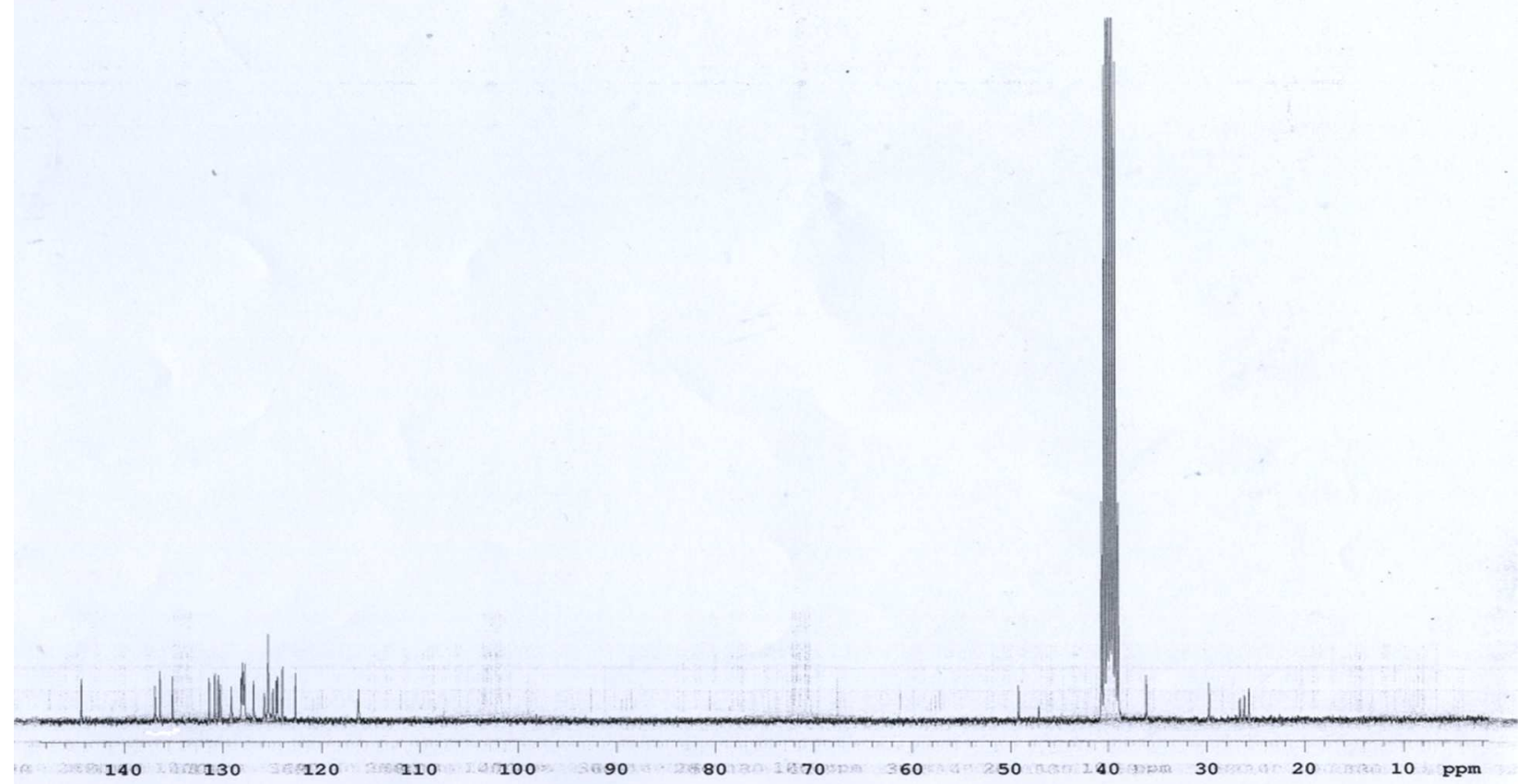

Figure S2. ${ }^{13} \mathrm{C}-\mathrm{NMR}$ spectrum of PPP. 


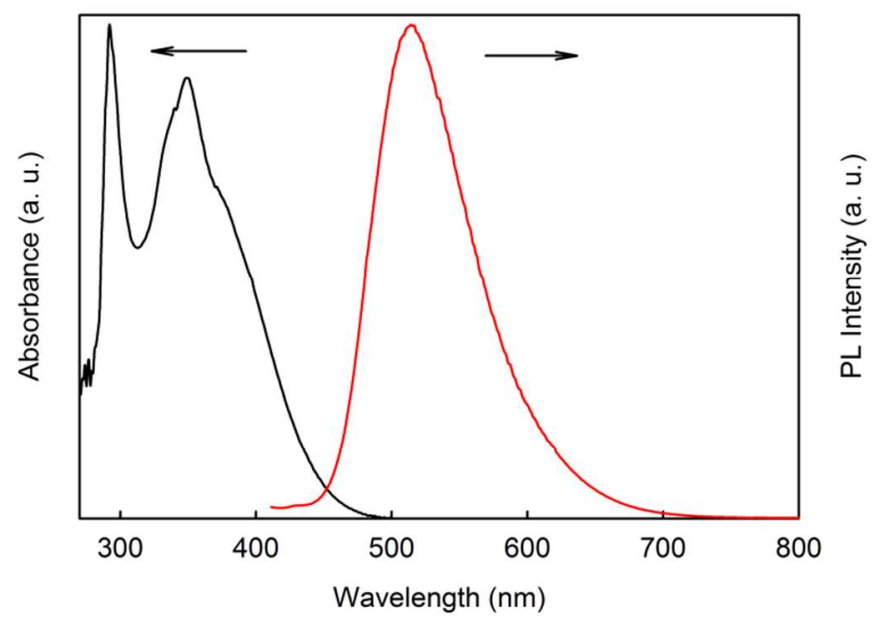

Figure S3. Thin film absorption and PL spectra of PPP.

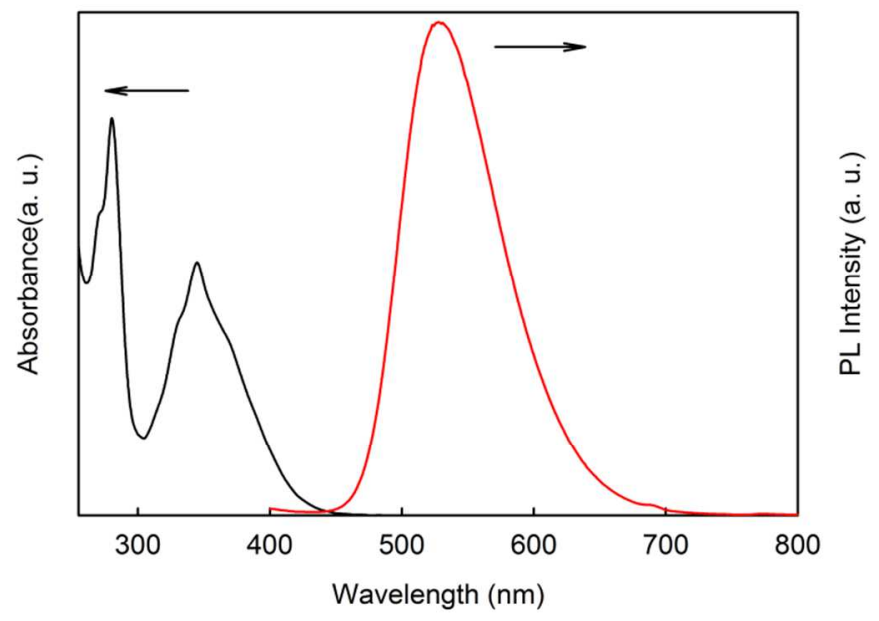

Figure S4. Absorption and PL spectra of PPP in DCM solution. 


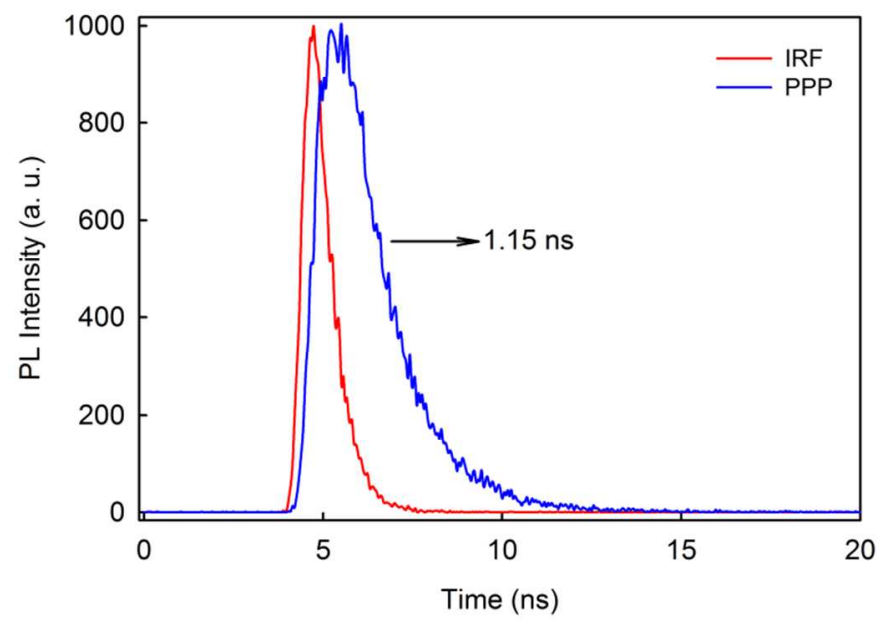

Figure S5. Transient PL spectra of PPP in oxygen-free toluene solution.

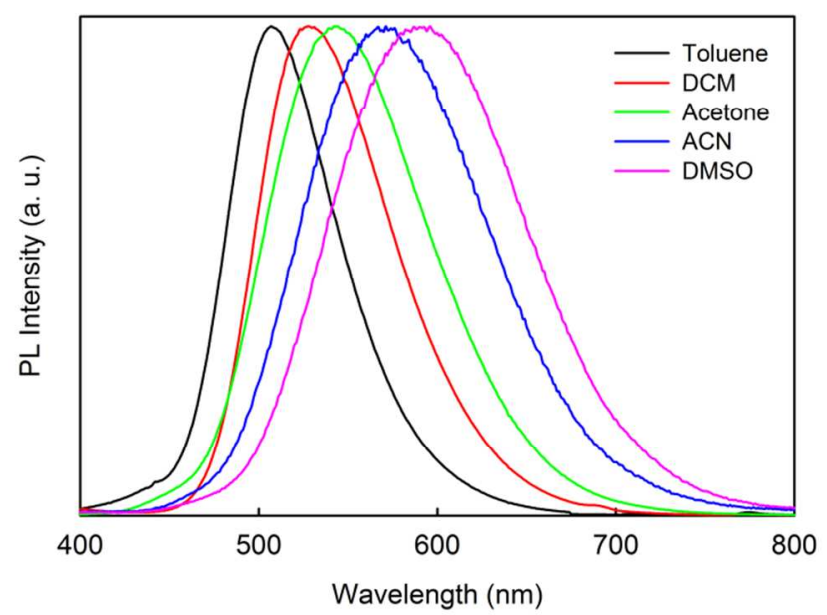

Figure S6. Emission spectra of PPP in different solvents. 


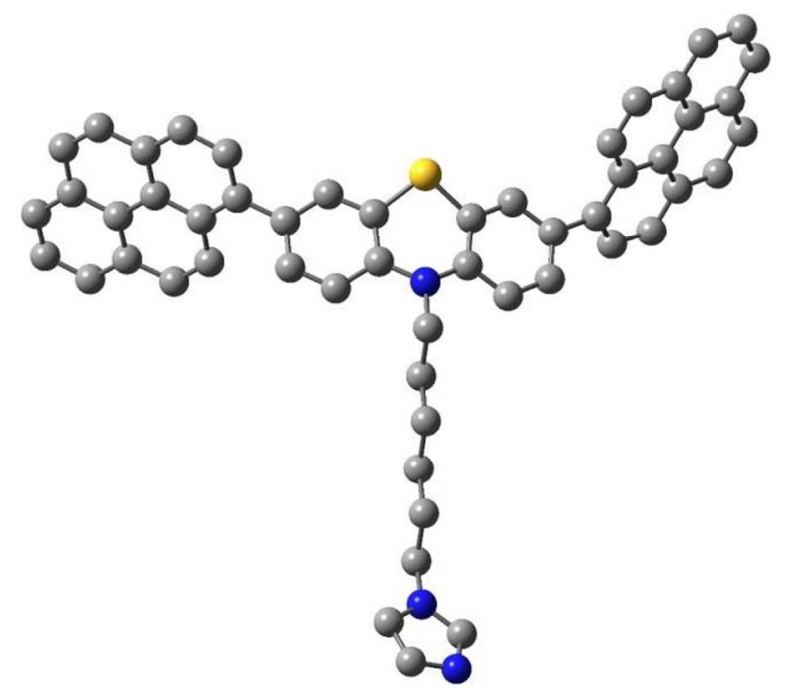

Figure S7. The DFT optimized ground state geometry of the compound PPP.

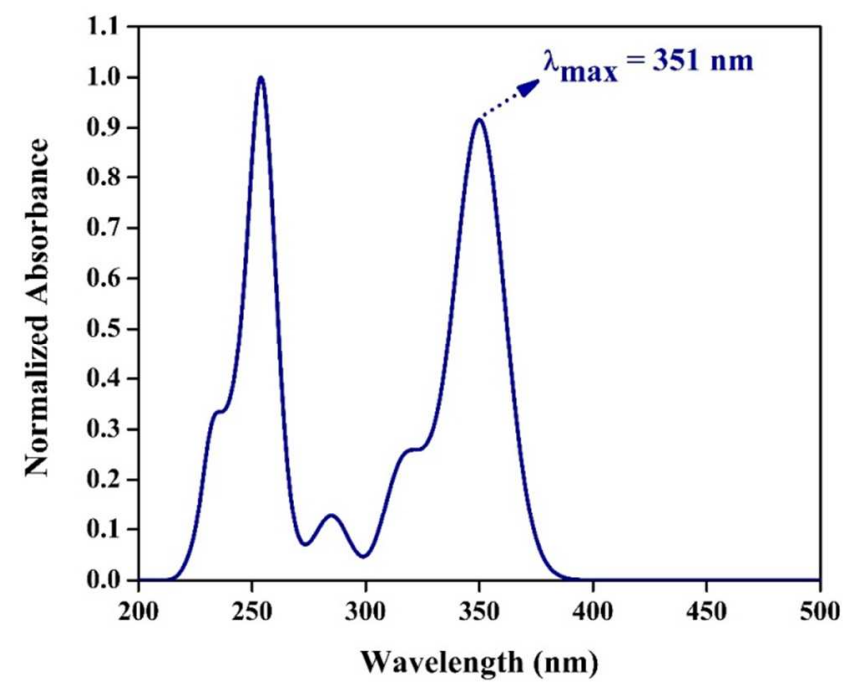

Figure S8. The UV-visible absorption spectrum of PPP simulated in dichloromethane. 


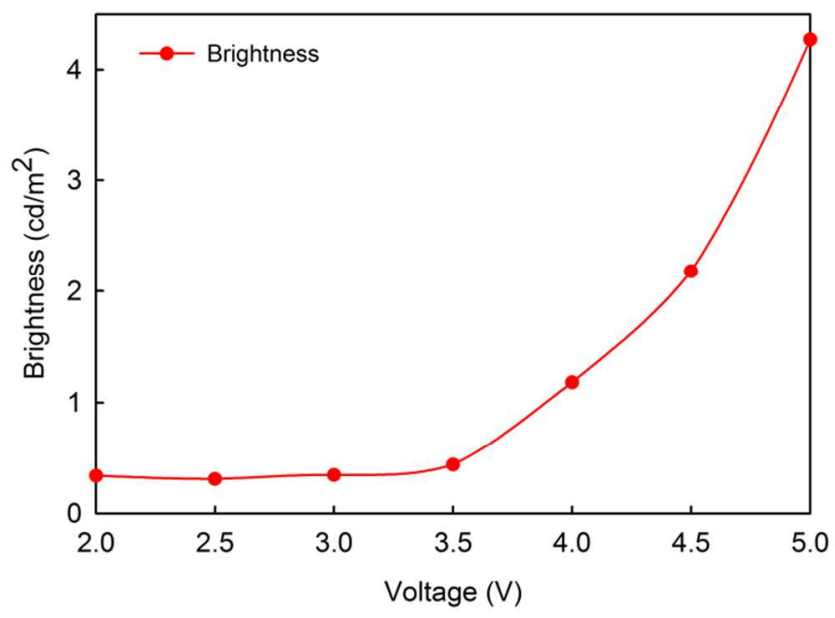

Figure S9. Turn-on voltage of LEC device in higher magnification.

Table S1. The results of TDDFT calculations.

$\begin{array}{ccccc}\text { Transition } & \begin{array}{c}\lambda_{\text {cal }} \\ (\mathrm{nm})\end{array} & \boldsymbol{f} & \begin{array}{c}\text { CI } \\ \text { Coefficient }\end{array} & \begin{array}{c}\text { Dominant } \\ \text { Contribution (\%) }\end{array} \\ \mathrm{S}_{0} \rightarrow \mathrm{S}_{1} & 351 & 1.3760 & 0.5357 & \text { HOMO } \rightarrow \text { LUMO (57) } \\ \mathrm{S}_{0} \rightarrow \mathrm{S}_{2} & 333 & 0.2439 & 0.4813 & \text { HOMO } \rightarrow \text { LUMO+1 (46) } \\ \mathrm{S}_{0} \rightarrow \mathrm{S}_{3} & 316 & 0.2989 & 0.3624 & \text { HOMO } \rightarrow \text { LUMO+4 (26) } \\ \mathrm{S}_{0} \rightarrow \mathrm{S}_{4} & 315 & 0.0280 & 0.3416 & \text { HOMO-1 } \rightarrow \text { LUMO+3 (23) } \\ \mathrm{S}_{0} \rightarrow \mathrm{S}_{5} & 315 & 0.0218 & 0.2657 & \text { HOMO-1 } \rightarrow \text { LUMO+2 (19) }\end{array}$

Calculated absorption wavelengths $\left(\lambda_{\text {cal }}\right)$, oscillator strengths $(f)$, and coefficient of configuration interaction (CI) with the dominant contribution obtained at TD-CAM-B3LYP/6-31G(d) level. 